\title{
READ ME
}

This manuscript is a preprint and so is not the peer-reviewed version. Please do not reference the preprint version as the manuscript has undergone peer-review and was recently accepted for publication in the journal Addiction. The reference is:

Tabri, N., Xuereb, S., Cringle, N., \& Clark, L. (in press). Associations between financial gambling motives, gambling frequency, and level of problem gambling: A meta-analytic review. Addiction. https://doi.org/10.1111/add.15642

Please only reference the published version. Thanks! 
Revisiting the role of financial motives in disordered gambling: A meta-analytic review

\author{
Nassim Tabri ${ }^{1 *}$ \\ Silas Xuereb ${ }^{1}$ \\ Natalie Cringle ${ }^{2}$ \\ and \\ Luke Clark ${ }^{2,3}$
}

${ }^{1}$ Department of Psychology, Carleton University, Ottawa, ON, Canada

${ }^{2}$ Centre for Gambling Research at UBC, Department of Psychology, University of British Columbia,Vancouver, BC, Canada

${ }^{3}$ Djavad Mowafaghian Centre for Brain Health, University of British Columbia, Vancouver, BC, Canada

*Correspondence concerning this article should be addressed to Nassim Tabri, Department of Psychology, Carleton University, 1125 Colonel By Drive, Ottawa, Ontario, Canada, K1S 5B6. E-mail: nassim.tabri@ carleton.ca

Competing interests and constraints:

All authors report no constraints on publishing and no competing interests.

Word count $=3469 / 3500$ (excludes Abstract, Tables, Figures, and References) 


\begin{abstract}
Aims: Money is central to psychological definitions of gambling, but contemporary accounts of disordered gambling are ambiguous regarding the role of financial motives for gambling. The aims of the current research were to obtain meta-analytic weighted effect sizes for zeroorder associations of financial motives against disordered gambling and gambling frequency, as well as partial associations after controlling for other motives (e.g. coping).
\end{abstract}

Design: A meta-analysis of the available literature through October 2019 was undertaken. Studies were identified from multiple sources (e.g., database search, consulting other researchers). PRISMA standards were followed when screening identified records and extracting relevant data. The data analytic plan was pre-registered.

Setting: Cross-sectional studies that involved student, community, and clinical samples of people who gamble.

Participants: Forty-one studies were included with 32,997 participants from different countries.

Measurements: Validated self-report measures of financial motives for gambling alongside measures of either problem gambling and/or gambling frequency.

Findings: Financial motives for gambling were positively associated with both disordered gambling, $r=.34,[.30, .38], p=1.04^{\mathrm{e}-61}$, and gambling frequency, $r=.29,[.20, .37], p=$ $1.70^{\mathrm{e}-13}$, with moderate effect sizes. The partial associations after controlling for overlapping variance with other gambling motives were also positive (disordered gambling: $\beta=.18$, [.14, $.23], p=2.53^{\mathrm{e}-15}$; gambling frequency: $\beta=.16$, $\left.[.08, .24], p=9.45^{\mathrm{e}-5}\right)$, with small-to-moderate effect sizes. The effect sizes were heterogenous and the extent of heterogeneity was high. Moderator analyses of the zero-order association involving gambling frequency indicated that effect sizes were larger for studies that used the Gambling Motives Questionnaire-Financial relative to studies that developed their own gambling motives measure. No further moderators were statistically significant.

Conclusions: Financial motives are reliably and positively associated with both disordered gambling and gambling involvement and should be incorporated into etiological models of gambling disorder.

Word count $=296 / 300$

Keywords: Meta-analysis; gambling motives; financial motives for gambling; disordered gambling; gambling involvement; 


\section{Revisiting the role of financial motives in disordered gambling: A meta-analytic review}

Definitions of gambling — both legal and psychological—center around money both in the wager and prize (1). To a layperson, the question "Why do people gamble?" might trigger an obvious answer "To win money". Indeed, in studies asking gamblers about their motives for gambling, winning money was typically the most endorsed item, among both regular gamblers and in people with gambling problems $(2,3)$. However, contemporary etiological theories either disregard or underspecify the role of financial motives in disordered gambling. Likewise, mixed results characterize the empirical literature on financial motives in relation to disordered gambling. The reason may be due, at least in part, to historical overlap between research on disordered gambling and substance use disorders. Early interest in gambling motives (4) was inspired by an analogy to social (e.g., to spend time with friends), enhancement (e.g., for excitement), and coping (e.g., to escape negative affect) motives for using alcohol (e.g., 5,6). In this research, disordered gambling and alcohol use have each been shown to be especially associated with coping motives $(4,7,8)$, which in turn points to negative reinforcement as a key process in addiction (e.g., 9,10).

The three-factor formulation of gambling motives measured using the Gambling Motives Questionnaire (GMQ; 11) was subsequently extended to include financial motives (GMQ-F; 8). Other widely used scales for assessing gambling motives also include a financial component, including the Gambling Motives Scale (GMS; 12) grounded in selfdetermination theory, the Gambling Outcomes Expectancies Scale (GOES; 13), and the Reasons for Gambling Questionnaire (RGQ; 14). Nevertheless, financial motives are often considered secondary compared to social, enhancement, and coping motives for gambling (13). Financial motives have also yet to be meaningfully incorporated into etiological models of disordered gambling. For example, what is arguably the most influential contemporary 
biopsychosocial framework of disordered gambling — the Pathways Model (15) — is entirely silent about the roles of either money or financial attitudes.

Other accounts acknowledge that financial motives may be inextricably linked to other gambling motives. Walker, Schellink, and Anjoul (16) noted that the prospect of winning money may be a prerequisite for gambling's other effects, including its social purpose, making it fun and exciting (i.e., enhancement), and offering a source of escape (i.e., coping). In turn, financial motives may amplify these other sources of reinforcement: winning provides more enhancement or escape for a gambler with high financial motives (e.g., 8,17). By these accounts, the "chance to win money" may actually be the core motive underlying gambling, from which other motives originate $(16,18)$.

These ambiguities around the fundamental role of financial motives persist in recent empirical work. Across different study populations and including large sample sizes, some studies have reported positive correlations between financial motives and disordered gambling severity, which remained after statistically controlling for multiple covariates including the shared variance with other gambling motives (e.g., 19-21). However, other studies reported that a positive bivariate association was attenuated when the shared variance with other motives was partialed out (e.g., 22-24), and some other studies have failed to detect basic differences in financial motives between groups with and without gambling problems $(25,26)$. In one study $(27)$, the proportion of people who endorsed a single item 'to win money' was lower among those with gambling problems compared to those who gamble without problems. It is possible that some of the inconsistencies may reflect psychometric issues with the measurement of financial motives, such as the potential for ceiling effects, or the possibility that financial motives may change over the transition from recreational to disordered gambling (e.g., as a consequence of rising debts). Accordingly, it is informative to 
examine financial motives in relation to both disordered gambling severity and basic gambling frequency.

In the current research, we used meta-analysis to examine the magnitude of the zeroorder association between financial motives and disordered gambling severity. We also explored sources of heterogeneity across studies. Moderators were sample characteristics and the questionnaire used to measure financial motives. In addition, we used meta-analysis to examine the magnitude of the partial association between financial motives and disordered gambling severity after statistically controlling for shared variance with other motives. Furthermore, parallel analyses were conducted for the zero-order and partial associations between financial motives and gambling frequency. The analyses were pre-registered: https://osf.io/mrndq.

\section{Method}

\section{Inclusion and exclusion criteria}

Studies were included if they were (a) empirical, (b) measured financial motives for gambling, (c) measured disordered gambling severity, gambling frequency, or both, and (d) written in English or French. Studies were excluded if they were a) experimental or qualitative, (b) measured gambling motives with a single item or an open-ended question, (c) published before 1980 (the year pathological gambling was recognized as a diagnosis in the Diagnostic and Statistical Manual of Mental Disorders, 3rd edition), or (d) the data were included in another study that was included in our review. Studies meeting all the inclusion criteria and none of the exclusion criteria were retained for further inspection.

\section{Selection of studies}

Studies were located via three sources. First, a comprehensive database search was conducted in October 2019 to identify relevant records using PsycINFO, PubMed and ProQuest Dissertations and Theses databases (in order to capture relevant grey academic 
literature). We identified search terms for financial motives and gambling to search the title and abstract of records in each database. For example, in PsycINFO, the boolean phrase for financial motives was (ab(Motiv*) OR ab(Reason*) OR ab(Expectan*) OR ti(Motiv*) OR ti(Reason*) OR ti(Expectan*)) AND (ab(finan*) OR ab(mone*) OR ti(finan*) OR ti(mone*)). The PsychINFO boolean phrase for gambling was (ab(gambling) OR ab(Pathological Gambl*) OR ab(Disordered Gambl*) OR ti(gambling) OR ti(Pathological

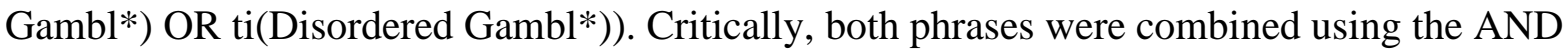
operator. The boolean phrases for the remaining databases are available on OSF (https://osf.io/atc2v/?view_only=bc66a47aaa3541bbb0fb28484a4cbf57). The comprehensive database search identified 373 records.

Second, records were located based on the expert knowledge of the research team (e.g., recently accepted or in press records as well as unpublished data) from which 44 potential records were identified. Third, three records were located by requesting unpublished and in press studies from experts in the field via the Gambling Issues International listserv as well as on Twitter.

As described in the PRISMA diagram (see Figure 1), a total of 420 records were located from the three sources. After removing duplicates, 388 unique records remained. For the database search results, two independent coders coded the abstracts according to the inclusion and exclusion criteria. The agreement rate between the two coders was $95.9 \%$ and their inter-rater reliability was moderate-to-high, Kappa $=.83, p<.01$. When the coders' ratings diverged, they were discussed until consensus was achieved. One of the coders also coded the abstracts of remaining studies. This process resulted in a set of 104 records that were eligible for full-text screening.

We excluded 26 papers through full-text review. Of the remaining papers, 63 did not have all the required data needed to obtain the effect sizes for the meta-analyses. As such, our 
team contacted the corresponding authors of 60 eligible records (contact information could not be obtained for three records) to request additional data that would be required. The requested data were means and $S D$ s of study variables and their intercorrelations. In total, we obtained relevant data from 41 records for the meta-analysis of the zero-order associations between financial motives and disordered gambling severity (see Table 1). These 41 records yielded 44 effect sizes; 34 effect sizes were available for the partial association after controlling for shared variance with other gambling motives (i.e., social, coping and enhancement). Of note, for the zero-order and partial associations, 17 and 13 effect sizes, respectively, were calculated based on additional information requested from the authors.

For financial motives and gambling frequency, we identified 17 effect sizes for the zero-order association, and 10 effect sizes for the partial association controlling for shared variance with other gambling motives. Of note, for the zero-order and partial associations, respectively, 11 and 7 effect sizes were derived from additional information requested from the authors.

\section{Effect size information}

We used the Pearson correlation coefficient $(r)$ as the effect size to index the zeroorder association between financial motives and disordered gambling severity. The $r$ s were extracted from each study. We used the standardized regression coefficient $(\beta)$ as the effect size to index the relation between financial motives and disordered gambling severity after statistically controlling for other gambling motives (i.e., social, coping, and enhancement). The $\beta$ s were calculated from more detailed information (i.e., descriptive statistics and correlations) directly obtained from the authors of each study - this was necessary because many studies did not report the information needed to calculate the partial relations. The 
same effect sizes were used to index the zero-order association and partial association between financial motives and gambling frequency.

\section{Meta-analytic procedure}

In line with recommendations (see 28), $r$ was transformed to Fisher's $r\left(Z_{r}\right)$ in the meta-analyses and results were back transformed to Pearson $r$ for interpretation. In the analyses, $Z_{r}$ effect sizes were pooled and weighted by their inverse-variance (1/SE $E^{2}$. The $S E$ of each $Z_{r}$ was calculated using the formula provided by:

$$
S E_{Z r}=\sqrt{(N-3)}
$$

where $N$ is the sample size.

We examined the variability between the effect sizes using the test of heterogeneity ( $Q$-statistic). When there was evidence of variability among the effect sizes, the $I^{2}$ statistic was used to quantify the extent of variability. We examined publication bias by testing whether there were significant differences between published and unpublished effect sizes using the meta-analysis analogue to ANOVA, along with Funnel Plots and Egger's Test. The funnel plots are available on OSF:

\section{https://osf.io/atc2v/?view_only=bc66a47aaa3541bbb0fb28484a4cbf57}

Moderator analyses were conducted using the meta-analysis analogue to regression (i.e., meta-regression) to examine predictors of between-study variability among the effect sizes. In the meta-regression, moderators were examined simultaneously to control for their overlapping variance. Mean age of the sample, and percentage of women in each sample, were included as continuous moderators. Country of origin was re-coded as geographical region and included as a categorical moderator using dummy codes in which the reference group was North America $(k=22)$. The remaining categories were Australasia $(k=9)$, Europe $(k=8)$, Asia $(k=4)$, and South America (Argentina; $k=1)$. Publication status was included as a categorical moderator with two levels (published vs. unpublished). The measure of 
financial motives was included as a categorical moderator using dummy codes with the GMQ-F $(k=22)$ as the reference category. The remaining categories were for authordeveloped measures $(k=6)$, the Gambling Outcomes Expectancies Scale $(k=5)$, and Other $(k=11)$. The Other category included effect sizes that used Lee et al.'s (2007) gambling motivation scale $(k=3)$, the Gambling Motives Attitudes and Behaviors scale $(k=2)$, Chantal et al.'s (12) Gambling Motivation Scale $(k=2)$, the Reasons for Gambling Questionnaire $(k=2)$, the Gambling Expectancy Questionnaire $(k=1)$, and the Motivational Scale for Fantasy Football Participation $(k=1)$. We also sought to examine sample type (e.g., clinical vs. community) as a moderator, but most studies involved community samples of people who gamble whereas one involved a clinical sample of disordered gamblers and one other involved a vulnerable population (see Table 1), which precluded examining sample type as a moderator.

For meta-analyses that pooled $\beta \mathrm{s}$, they were also each weighted by their inversevariance. The $S E$ of each $\beta$ was calculated using the formula provided by Cohen, Cohen, West, \& Aiken (29):

$$
S E_{\beta i}=\sqrt{\frac{1-R_{y}^{2}}{n-k-1}} \sqrt{\frac{1}{1-R_{i}^{2}}}
$$

where $R_{y}^{2}$ is the variance explained in the dependent variable by the independent variables in the regression model, $R_{i}^{2}$ is the variance explained in the independent variable of interest by the remaining independent variables in the regression model, $n$ is the sample size, and $k$ is the number of independent variables in the regression model.

We interpreted the magnitude of each effect ( $r$ and $\beta$ ) size according to Cohen's (30) conventions for correlation coefficients, where .10 is small, .30 is moderate, and .50 is large. 
To allow us to generalize our results beyond the current sample, a random-effects model was used in the meta-analyses. All meta-analyses were conducted using JASP (31).

\section{Results}

\section{Descriptive information for each effect size}

Table 1 includes sample demographic information (age, gender composition, and country) associated with each effect size. Mean age and gender (\% female) in each sample were recorded as continuous variables. Country was recorded as a categorical variable, and $50 \%$ of the effect sizes were drawn from North America ( $k=22$; i.e., Canada and USA).

Table 1 also includes study-level information, including publication status $(81.8 \%$ were published; $k=36$ ) and the key measures used to assess financial gambling motives and disordered gambling severity. The most common measures were the GMQ-F (50\%, $k=22)$ and the Problem Gambling Severity Index $(68 \%, k=30)$. A smaller subset of effect sizes included a measure of gambling frequency $(k=17)$ and most $(88.2 \% ; k=15)$ assessed gambling frequency using an author-developed self-report questionnaire.

\section{Financial motives and disordered gambling severity}

Mean weighted zero-order association. Financial motives for gambling were positively associated with disordered gambling severity, $r=.34,[.30, .38], p=1.04^{\mathrm{e}-61}, k=44$. The mean effect size was moderate (see Figure 1 for forest plot).

Publication bias. There was no difference between published $(k=36)$ and unpublished $(k=8)$ effect sizes, $Q(1)=.09, p=.77$, and Egger's test of funnel plot asymmetry was not statistically significant, $z=.72$ and $p=.74$. Thus, there was no evidence of publication bias.

Moderator analysis. The effect sizes were heterogeneous, $Q(43)=837.70, p=6.69^{\mathrm{e}-}$ ${ }^{148}$, and the extent of heterogeneity was high, $I^{2}=92.39 \%$. Results of the moderator analysis are reported in Table 2. The omnibus test of the meta-regression model was not statistically 
significant, $Q(10)=9.77, p=.46$, and none of the tested moderators were statistically significant. Thus, our included moderators did not explain variation between the effect sizes.

Mean weighted partial association. For the partial association after controlling for shared variance with other motives, financial motives for gambling was positively associated with disordered gambling severity, $\beta=.18,[.14, .23], p=2.53^{\mathrm{e}-15}, k=34$. The mean effect size was small-to-moderate (see Figure 3 for forest plot). The effect sizes were heterogeneous, $Q(33)=505.46, p=6.24^{\mathrm{e}-86}$, and the extent of heterogeneity was high, $I^{2}=$ $90.89 \%$.

\section{Financial motives and gambling frequency}

Mean weighted zero-order association. Financial motives for gambling were positively associated with gambling frequency, $r=.29$, [.20, .37], $p=1.70^{\mathrm{e}-13}, k=19$. The mean effect size was moderate (see Figure 4 for forest plot).

Publication bias. Because all effect sizes were drawn from published research, we could not test the difference between published and unpublished effect sizes. Nevertheless, Egger's test of funnel plot asymmetry was not statistically significant, $z=1.01$ and $p=.31$. Thus, we find no evidence of publication bias.

Moderator analysis. The effect sizes were heterogeneous, $Q(16)=434.04 p=2.61^{\mathrm{e}-}$ ${ }^{82}$, and the extent of heterogeneity was high, $I^{2}=96.91 \%$. Results of the moderator analysis are reported in Table 2. Of note, the omnibus test of the meta-regression model was statistically significant, $Q(7)=19.75, p=.006$. There was a statistically significant difference between studies that used the GMQ-F and studies that used an author-developed measure of financial gambling motives (see Table 2) such that GMQ-F effect sizes were larger. None of the remaining moderators were statistically significant.

Mean weighted partial association. For the partial association, financial motives for gambling were positively associated with gambling frequency, $\beta=.16,[.08, .24], p=9.45^{\mathrm{e}-5}$, 
$k=10$. The mean effect size was small-to-moderate (see Figure 5 for forest plot). The effect sizes were heterogeneous, $Q(9)=78.39, p=3.37^{\mathrm{e}-13}$, and the extent of heterogeneity was high, $I^{2}=92.14 \%$.

\section{Discussion}

Our systematic search identified 44 effect sizes for the association between financial motives and disordered gambling severity. Meta-analysis of these effect sizes indicated a reliable association of moderate effect size. We ruled out the possibility that the zero-order association was due to shared variance between financial and other motives (social, enhancement, and coping) using a meta-analysis of partial associations. We identified 19 effect sizes for the association between financial motives and gambling frequency, and metaanalysis indicated a reliable association of moderate effect size that could not be explained by covariation with other motives. We observed no evidence of publication bias but a high level of heterogeneity in the primary research, which corroborated our impression of a mixed literature. Thus, the results highlight the unique contribution of financial motives for understanding disordered gambling and gambling involvement. Our findings refute the mainstream idea, inspired partly by research on alcohol and the original GMQ, that it is coping motives that are dominant in gambling addiction.

Of note, none of the tested moderators (age, gender, geographical region, and financial motives questionnaire) for the relationship with disordered gambling accounted for a substantial portion of heterogeneity between the effect sizes. The only moderator was the type of financial motives questionnaire for the association involving gambling frequency. More specifically, effect sizes were larger for studies of gambling frequency using the GMQF relative to studies using an author-developed motives measure. Because the heterogeneity reflected differences in the magnitude of positive associations (see Figures 2 and 4), it is possible that unexamined substantive factors, such as individual differences in attitudes 
towards money and objective financial success in each sample, may help explain differences between the effect sizes. For instance, there is some evidence that people who view money as an important indicator of success, prestige, and power are more likely to gamble and to have gambling problems $(15,65)$. Although the link between money attitudes and gambling motives is yet to be examined, the magnitude of the positive association between financial motives and disordered gambling and gambling involvement may be larger in samples of people who view money as an indicator of success, prestige, and power.

Likewise, another factor that may help explain the heterogeneity is the extent to which gamblers have a financially focused self-concept (i.e., they place overriding importance on financial success for self-definition and self-worth). Gamblers high (relative to low) in financial focus are more likely to feel financially deprived, to gamble for financial gain, and to have gambling problems (58). Furthermore, across both non-disordered (66) and disordered (67) gamblers, those who are more financially focused tend to have more etiological risk factors (from the Pathways Model) compared to their less financially focused counterparts. Moreover, in a related line of research on personal relative deprivation (68), there is emerging evidence that people who feel financially deprived are more likely to gamble for financial gain and to develop gambling problems because feeling financially deprived increases delay-discounting of monetary rewards (i.e., preference for immediate smaller rewards relative to delayed larger rewards; 69 ). This relation has been shown to be stronger among gamblers who believe they have a low capacity for economic mobility via conventional means (57) as well as among gamblers who have a financially focused selfconcept (70). Accordingly, effect sizes may be larger in samples of gamblers who are more financially focused and who feel more financially deprived.

Importantly, however, attitudes towards money and financial success have received little attention among the included studies as well as in gambling research more broadly, and 
so we could not examine whether they explain heterogeneity between the effect sizes.

Critically, the little attention to attitudes towards money and financial success in prior research corresponds with the neglect of financial gambling motives in theories of gambling addiction. Therefore, we call for more research on the factors that place people at greater risk to gamble for financial gain and to incorporate these factors into contemporary etiological models of gambling addiction.

Our review also identified two further limitations of the literature examining financial motives. First, most studies in the financial gambling motives literature involved general community samples. We found few data in treatment-seeking gamblers, or in vulnerable populations such as ethnic minorities and youths (e.g., 32). This is a critical gap in the literature as some evidence, for instance, indicates that members of ethnic and racial minorities are more likely to gamble for financial gain (e.g., 33). Second, extant research on financial gambling motives is almost exclusively based on cross-sectional research designs, which limits causal inferences. To our knowledge, there is only one published longitudinal study, which showed that financial motives do not prospectively predict gambling involvement and disordered gambling severity among community gamblers when shared variance with other motives was partialed out (34). Thus, we call for more longitudinal research that examines the gambling-related consequences of financial motives.

In sum, our meta-analytic review showed robust concurrent positive associations of moderate effect size between financial motives on the one hand and disordered gambling and gambling involvement on the other hand. 


\section{References}

1. Reber AS. The EVF Model: A Novel Framework for Understanding Gambling and, by Extension, Poker. 16(1):18.

2. McGrath DS, Neilson T, Lee K, Rash CL, Rad M. Associations between the HEXACO model of personality and gambling involvement, motivations to gamble, and gambling severity in young adult gamblers. J Behav Addict. 2018 Jun;7(2):392-400.

3. Neighbors C. Exploring College Student Gambling Motivation. J Gambl Stud. 2002;18(4):10.

4. Milosevic A, Ledgerwood DM. The subtyping of pathological gambling: A comprehensive review. Clin Psychol Rev. 2010 Dec 1;30(8):988-98.

5. Cooper ML. Motivations for alcohol use among adolescents: Development and validation of a four-factor model. Psychol Assess. 1994;6(2):117-28.

6. Fernandes-Jesus M, Beccaria F, Demant J, Fleig L, Menezes I, Scholz U, et al. Validation of the Drinking Motives Questionnaire - Revised in six European countries. Addict Behav. 2016 Nov;62:91-8.

7. Schellenberg BJI, McGrath DS, Dechant K. The Gambling Motives Questionnaire financial: factor structure, measurement invariance, and relationships with gambling behaviour. Int Gambl Stud. 2016 Jan 2;16(1):1-16.

8. Dechant K. Show Me the Money: Incorporating Financial Motives into the Gambling Motives Questionnaire. J Gambl Stud. 2014 Dec;30(4):949-65.

9. Baker TB, Morse E, Sherman JE. The motivation to use drugs: a psychobiological analysis of urges. Neb Symp Motiv Neb Symp Motiv. 1986;34:257-323.

10. Koob GF. Negative reinforcement in drug addiction: the darkness within. Curr Opin Neurobiol. 2013 Aug 1;23(4):559-63.

11. Stewart SH, Zack M. Development and psychometric evaluation of a three-dimensional Gambling Motives Questionnaire. Addiction. 2008;103(7):1110-7.

12. Chantal $Y$, Vallerand RJ, Vallères EF. Assessing Motivation to Gamble: On the Development and Validation of the Gambling Motivation Scale. Loisir Société Soc Leis. 1994 Jan 1;17(1):189-212.

13. Flack M, Morris M. Problem Gambling: One for the Money...? J Gambl Stud. 2015 Dec;31(4):1561-78.

14. Wardle H, National Centre for Social Research (Great Britain), Great Britain, Gambling Commission. British gambling prevalence survey 2010. London: National Centre for Social Research; 2011.

15. Blaszczynski A, Nower L. A pathways model of problem and pathological gambling. Addiction. 2002;97(5):487-99.

16. Walker M, Schellink T, Anjoul F. Explaining Why People Gamble. In: Zangeneh M, Blaszczynski A, Turner NE, editors. In the Pursuit of Winning [Internet]. Boston, MA: Springer US; 2008 [cited 2020 Sep 16]. p. 11-31. Available from: http://link.springer.com/10.1007/978-0-387-72173-6_2

17. Wulfert E, Franco C, Williams K, Roland B, Maxson JH. The role of money in the excitement of gambling. Psychol Addict Behav J Soc Psychol Addict Behav. 2008 Sep;22(3):380-90.

18. Binde P. Why people gamble: a model with five motivational dimensions. Int Gambl Stud. 2013 Apr 1;13(1):81-97.

19. Barrault S, Mathieu S, Brunault P, Varescon I. Does gambling type moderate the links between problem gambling, emotion regulation, anxiety, depression and gambling motives. Int Gambl Stud. 2019 Jan 2;19(1):54-68.

20. Marmurek HHC, Switzer J, D'Alvise J. A Comparison of University Student and Community Gamblers- Motivations, impulsivity, and gambling cognitions. J Behav Addict. 2014;3(1):54-64.

21. van der Maas M, Mann RE, McCready J, Matheson FI, Turner NE, Hamilton HA, et al. Problem Gambling in a Sample of Older Adult Casino Gamblers: Associations With Gambling Participation and Motivations. J Geriatr Psychiatry Neurol. 2017 Jan 1;30(1):3-10. 
22. Flack M, Stevens M. Gambling motivation: comparisons across gender and preferred activity. Int Gambl Stud. 2019 Jan 2;19(1):69-84.

23. Kim HS, Rash CL, McGrath DS. The dishonest gambler: Low HEXACO honestyhumility and gambling severity in a community sample of gamblers: HEXACO honestyhumility and gambling severity. Personal Ment Health. 2018 Nov;12(4):355-64.

24. Kim HS, Poole JC, Hodgins DC, McGrath DS, Dobson KS. Betting to deal: coping motives mediate the relationship between urgency and Problem gambling severity. Addict Res Theory. 2019 Mar 4;27(2):95-103.

25. Clarke D. Impulsiveness, Locus of Control, Motivation and Problem Gambling. J Gambl Stud. 2004;20(4):319-45.

26. Ladouceur R, Arsenault C, Dube D. Psychological Characteristics of Volunteers in Studies on Gambling. J Gambl Stud. 1997;13(1):16.

27. Burlacu S, Romo L, Lucas $C$, Legauffre $C$. Motivation in gambling activities among French gamblers. Ann Med Psychol (Paris). 2013;171(6):410-3.

28. Lipsey MW, Wilson DB. The efficacy of psychological, educational, and behavioral treatment. Am Psychol. 1993;48(12):1181-209.

29. Cohen J, Cohen P, West SG, Aiken LS. Applied multiple regression/correlation analysis for the behavioral sciences, 3rd ed. Mahwah, NJ, US: Lawrence Erlbaum Associates Publishers; 2003. xxviii, 703 p. (Applied multiple regression/correlation analysis for the behavioral sciences, 3rd ed).

30. Cohen J. The effect size index: d. Stat Power Anal Behav Sci. 1988;2(1).

31. JASP Team. JASP (Version 0.13.1). 2020.

32. Hing N, Breen H, Gordon A, Russell A. Risk Factors for Problem Gambling Among Indigenous Australians: An Empirical Study. J Gambl Stud. 2014 Jun;30(2):387-402.

33. Clarke D, Tse S, Abbott M, Townsend S, Kingi P, Manaia W. Religion, Spirituality and Associations with Problem Gambling. N Z J Psychol. 2006;35(2):77-83.

34. Flack M, Morris M. The Temporal Stability and Predictive Ability of the Gambling Outcome Expectancies Scale (GOES): A Prospective Study. J Gambl Stud. 2016 Sep 1;32(3):923-33.

35. Barrada JR, Navas JF, Ruiz de Lara CM, Billieux J, Devos G, Perales JC.

Reconsidering the roots, structure, and implications of gambling motives: An integrative approach. Weinstein AM, editor. PLOS ONE. 2019 Feb 22;14(2):e0212695.

36. Browne M, Hing N, Rockloff M, Russell AMT, Greer N, Nicoll F, et al. A Multivariate Evaluation of 25 Proximal and Distal Risk-Factors for Gambling-Related Harm. J Clin Med. 2019 Apr 13;8(4):509.

37. Clarke D. Older Adults' Gambling Motivation and Problem Gambling: A Comparative Study. J Gambl Stud. 2008 Jun;24(2):175-92.

38. Devos G, Challet-Bouju G, Burnay J, Maurage P, Grall-Bronnec M, Billieux J. Adaptation and validation of the Gambling Motives Questionnaire-Financial (GMQ-F) in a sample of French-speaking gamblers. Int Gambl Stud. 2017 Jan 2;17(1):87-101.

39. Dodig D. Assessment challenges and determinants of adolescents' adverse psychosocial consequences of gambling. 2013;21:16.

40. Dowling NA, Oldenhof E, Shandley K, Youssef GJ, Vasiliadis S, Thomas SA, et al. The intergenerational transmission of problem gambling: The mediating role of offspring gambling expectancies and motives. Addict Behav. 2018 Feb;77:16-20.

41. Dwyer B, Shapiro SL, Drayer J. Daily Fantasy Football and Self-Reported Problem Behavior in the United States. J Gambl Stud. 2018 Sep;34(3):689-707.

42. Francis KL, Dowling NA, Jackson AC, Christensen DR, Wardle H. Gambling Motives: Application of the Reasons for Gambling Questionnaire in an Australian Population Survey. J Gambl Stud. 2015 Sep;31(3):807-23.

43. Hing N, Russell AMT. Proximal and Distal Risk Factors for Gambling Problems Specifically Associated with Electronic Gaming Machines. J Gambl Stud. 2020 Mar;36(1):277-95.

44. Hing N, Sproston K, Tran K, Russell AMT. Gambling Responsibly: Who Does It and To What End? J Gambl Stud. 2017 Mar;33(1):149-65. 
45. Hodgins DC, Racicot $\mathrm{S}$. The link between drinking and gambling among undergraduate university students. Psychol Addict Behav. 2013 Sep;27(3):885-92.

46. Hollingshead SJ, Kim HS, Wohl MJA, Derevensky JL. The Social Casino GamingGambling Link: Motivation for Playing Social Casino Games Determines Whether SelfReported Gambling Increases or Decreases Among Disordered Gamblers. J Gambl Issues. 2016 Aug 1;(33):52.

47. Hollingshead SJ, Wohl MJA, Santesso D. Do you read me? Including personalized behavioral feedback in pop-up messages does not enhance limit adherence among gamblers. Comput Hum Behav. 2019 May;94:122-30.

48. Hollingshead SJ, Amar M, Santesso D, Wohl MJA. When should players be taught to gamble responsibly? Timing of educational information upregulates responsible gambling intentions. Addict Res Theory. 2019 Nov 2;27(6):507-14.

49. Hollingshead S. Does pop-up message content matter? An examination of the effectiveness of informing gamblers about their monetary losses on player limit adherence. [Ottawa, ON]: Carleton University; 2017.

50. Huic A, Dodig Hundric D, Kranzelic V, Ricijas N. Problem Gambling among Adolescent Girls in Croatia-The Role of Different Psychosocial Predictors. Front Psychol. 2017 May 19;8:792.

51. Lee C-K, Chung N, Bernhard BJ. Examining the Structural Relationships Among Gambling Motivation, Passion, and Consequences of Internet Sports Betting. J Gambl Stud. 2014 Dec;30(4):845-58.

52. MacLaren V, Ellery M, Knoll T. Personality, gambling motives and cognitive distortions in electronic gambling machine players. Personal Individ Differ. 2015 Jan;73:24-8.

53. Pilatti A, Tuzinkievich FB. Valoración de las propiedades psicométricas del Cuestionario de Motivos de Apuestas en jóvenes y adultos argentinos. Adicciones. 2015 Mar 1;27(1):17.

54. Ricijas N, Dodig Hundric D, Huic A. Predictors of adverse gambling related consequences among adolescent boys. Child Youth Serv Rev. 2016 Aug;67:168-76.

55. Rodriguez LM, Neighbors C, Rinker DV, Tackett JL. Motivational Profiles of Gambling Behavior: Self-determination Theory, Gambling Motives, and Gambling Behavior. J Gambl Stud. 2015 Dec;31(4):1597-615.

56. Russell AMT, Hing N, Browne M. Risk Factors for Gambling Problems Specifically Associated with Sports Betting. J Gambl Stud. 2019 Dec;35(4):1211-28.

57. Smith MD, Rousu MC, Dion P. Internet Poker: Examining Motivations, Behaviors, Outcomes, and Player Traits using Structural Equations Analysis. J Gambl Issues [Internet]. 2012 Oct 1 [cited 2020 Jul 29];(27). Available from: https://jgi.camh.net/index.php/jgi/article/view/3870

58. Sundqvist K, Jonsson J, Wennberg P. Gambling Motives in a Representative Swedish Sample of Risk Gamblers. J Gambl Stud. 2016 Dec;32(4):1231-41.

59. Tabri N, Dupuis DR, Kim HS, Wohl MJA. Economic mobility moderates the effect of relative deprivation on financial gambling motives and disordered gambling. Int Gambl Stud. 2015 May 4;15(2):309-23.

60. Tabri N, Wohl MJA, Eddy KT, Thomas JJ. Me, myself and money: having a financially focused self-concept and its consequences for disordered gambling. Int Gambl Stud. 2017 Jan 2;17(1):30-50.

61. Tabri N, Hollingshead SJ, WohI MJA. A limit approaching pop-up message reduces gambling expenditures, except among players with a financially focused self-concept. Int Gambl Stud. 2019 May 4;19(2):327-38.

62. Tabri N, Wood RTA, Philander K, Wohl MJA. An examination of the validity and reliability of the Positive Play Scale: findings from a Canadian national study. Int Gambl Stud. 2020 May 3;20(2):282-95.

63. Tao VYK, Wu AMS, Cheung SF, Tong KK. Development of an Indigenous Inventory GMAB (Gambling Motives, Attitudes and Behaviors) for Chinese Gamblers: An Exploratory Study. J Gambl Stud. 2011 Mar;27(1):99-113.

64. Wohl MJA. My PlaySmart player survey. 
65. Wu AMS, Tang CS. Validation of the Chinese Version of the Gambling Motivation Scale (C-GMS). J Gambl Stud. 2011 Dec;27(4):709-24.

66. Wu AMS, Tao VYK, Tong K, Cheung SF. Psychometric evaluation of the inventory of Gambling Motives, Attitudes and Behaviours (GMAB) among Chinese gamblers. Int Gambl Stud. 2012 Dec;12(3):331-47. 


\begin{tabular}{|c|c|c|c|c|c|c|c|c|c|c|c|c|c|}
\hline & \multicolumn{8}{|c|}{ Sample and Study characteristics } & \multicolumn{5}{|c|}{ Effect size information } \\
\hline & \multicolumn{6}{|c|}{ Demographic information } & \multicolumn{2}{|c|}{ Measures } & \multicolumn{3}{|c|}{$\begin{array}{l}\text { Zero-order } \\
\text { associations }\end{array}$} & \multicolumn{2}{|c|}{ Partial associations } \\
\hline Label & Pub & Country & $\mathrm{N}$ & $\begin{array}{l}\text { Age } \\
\text { (yrs) }\end{array}$ & $\begin{array}{c}\% \\
\text { WO }\end{array}$ & Sample & $\begin{array}{c}\text { F- } \\
\text { Motives }\end{array}$ & GD & $\begin{array}{l}\mathrm{Zr} \\
\mathrm{GD}\end{array}$ & $\begin{array}{l}\mathrm{Zr} \\
\mathrm{GF}\end{array}$ & $\begin{array}{l}S E \\
\mathrm{Zr}\end{array}$ & $\begin{array}{c}\beta(S E) \\
\text { GD }\end{array}$ & $\begin{array}{c}\beta(S E) \\
\text { GF }\end{array}$ \\
\hline Barrada et al. 2019 (35) & Yes & Spain & 203 & 33.8 & 34 & ComClin & GMQ-F & SOGS & .34 & .45 & .07 & $.23(.05)$ & $.37(.07)$ \\
\hline Barrault et al., 2019 (19) & Yes & France & 287 & 24.1 & 0 & Gamb & GMQ-F & SOGS & .37 & - & .06 & $.3(.05)$ & - \\
\hline Browne et al., 2019 (36) & Yes & Canada & 1174 & 45.4 & 60.1 & Com & GOES & PGSI & .33 & .31 & .03 & $.21(.03)$ & $.19(.03)$ \\
\hline Clarke, 2008 (37) & Yes & $\begin{array}{c}\text { New } \\
\text { Zealand }\end{array}$ & 209 & 48.5 & 70.8 & Com & Other & SOGS & .24 & .11 & .07 & - & - \\
\hline
\end{tabular}




\begin{tabular}{|c|c|c|c|c|c|c|c|c|c|c|c|c|c|}
\hline Devos et al 2017 (1) (38) & No & $\begin{array}{l}\text { France, } \\
\text { Belgium }\end{array}$ & 22 & 41.3 & 18.2 & Clin & GMQ-F & PGSI & .35 & - & .23 & $.09(.26)$ & - \\
\hline Devos et al 2017 (2) (38) & Yes & France & 278 & 35.4 & 52.5 & Com & GMQ-F & PGSI & .16 & - & .06 & $-.09(.05)$ & - \\
\hline Dodig, 2013 (39) & Yes & Croatia & 1948 & 16.6 & 53 & Student & $\mathrm{AD}$ & Other & .66 & .60 & .02 & $.47(.02)$ & - \\
\hline Dowling et al., 2018 (40) & Yes & Australia & 823 & 21.2 & 43.5 & Student & Other & PGSI & .31 & - & .03 & - & - \\
\hline Dwyer et al., 2018 (41) & Yes & USA & 546 & 37.7 & 10 & Com & Other & PGSI & .33 & .16 & .04 & - & - \\
\hline Flack \& Morris, 2015 (13) & Yes & Australia & 1982 & 43.3 & 56 & Com & GOES & PGSI & .22 & .31 & .02 & $.06(.03)$ & $.13(.02)$ \\
\hline Flack \& Stevens, 2019 (18) & Yes & Australia & 1207 & 42.5 & 47.4 & Com & GOES & PGSI & .2 & .12 & .03 & $.05(.03)$ & $0(.03)$ \\
\hline Francis et al., 2015 (42) & Yes & Australia & 2796 & 54.5 & 39 & Com & Other & PGSI & .11 & .17 & .02 & - & - \\
\hline Hing \& Russell, 2020 (43) & Yes & Australia & 1932 & 41.8 & 46.9 & Com & GOES & PGSI & .65 & .38 & .02 & $.26(.03)$ & $.18(.03)$ \\
\hline
\end{tabular}




\begin{tabular}{|c|c|c|c|c|c|c|c|c|c|c|c|c|c|}
\hline Hing et al., 2014 (32) & Yes & Australia & 1259 & 38 & 58.4 & Indig & $\mathrm{AD}$ & PGSI & .16 & .14 & .03 & $.09(.03)$ & $-.01(.03)$ \\
\hline Hing et al., 2017 (44) & Yes & Australia & 860 & 49.5 & 32 & Gamb & $\mathrm{AD}$ & PGSI & .15 & - & .03 & $.11(.03)$ & - \\
\hline Hodgins \& Racicot, 2013 (45) & Yes & Canada & 122 & 21 & 69.4 & Student & GMQ-F & Other & .52 & .81 & .09 & $.12(.10)$ & $.43(.11)$ \\
\hline Hollingshead et al., 2016 (46) & No & USA & 271 & 31.6 & 67 & Com & GMQ-F & PGSI & .29 & - & .06 & $.20(.06)$ & - \\
\hline $\begin{array}{l}\text { Hollingshead et al., } 2019 \text { (1) } \\
\text { (47) }\end{array}$ & No & Canada & 124 & 57.5 & 53.2 & Gamb & GMQ-F & PGSI & .33 & - & .09 & $.17(.09)$ & - \\
\hline Hollingshead et al., 2019 (2) & No & Canada & 109 & 59.1 & 56.6 & Gamb & GMQ-F & PGSI & .23 & - & .10 & $.20(.09)$ & - \\
\hline $\begin{array}{l}\text { Hollingshead, Amar et al., } \\
2019 \text { (48) }\end{array}$ & No & Canada & 98 & 50.3 & 57.1 & Gamb & GMQ-F & PGSI & .4 & - & .10 & $.25(.09)$ & - \\
\hline Hollingshead, n.d. (49) & No & USA & 253 & 35 & 45.8 & Com & GMQ-F & PGSI & .4 & - & .06 & $.14(.07)$ & - \\
\hline Huic et al., 2017 (50) & Yes & Croatia & 1372 & 16.5 & 100 & Student & $\mathrm{AD}$ & Other & .38 & .38 & .03 & - & - \\
\hline
\end{tabular}




\begin{tabular}{|c|c|c|c|c|c|c|c|c|c|c|c|c|c|}
\hline Kim et al., 2018 (23) & Yes & USA & 205 & 33.2 & 39.2 & Com & GMQ-F & PGSI & .22 & - & .07 & $-.04(.07)$ & - \\
\hline Kim et al., 2019 (24) & Yes & USA & 564 & 36.1 & 52.1 & Com & GMQ-F & PGSI & .30 & - & .04 & $.05(.04)$ & - \\
\hline Lee et al., 2014 (51) & Yes & $\begin{array}{l}\text { South } \\
\text { Korea }\end{array}$ & 288 & 45.6 & 24 & Gamb & Other & Other & .48 & - & .06 & - & - \\
\hline MacLaren et al., 2015 (52) & Yes & Canada & 273 & 34 & 45.7 & Com & GMQ-F & PGSI & .44 & - & .06 & $.20(.06)$ & - \\
\hline $\begin{array}{l}\text { Marmurek et al., } 2014 \text { (1) } \\
\text { (20) }\end{array}$ & Yes & Canada & 123 & 23 & 48 & Student & Other & PGSI & .44 & - & .09 & $.31(.06)$ & - \\
\hline Marmurek et al., 2014 (2) & Yes & Canada & 113 & 46 & 54.9 & Com & Other & PGSI & .66 & - & .10 & $.47(.09)$ & - \\
\hline McGrath et al., 2018 (2) & Yes & Canada & 177 & 21 & 48.1 & Student & GMQ-F & PGSI & .48 & - & .08 & $.22(.07)$ & - \\
\hline $\begin{array}{l}\text { Pilatti \& Tuzinkievich, } 2015 \\
\text { (53) }\end{array}$ & Yes & Argentina & 270 & 29.4 & 70.7 & Com & GMQ-F & PGSI & .39 & - & .06 & $.22(.05)$ & - \\
\hline Ricijas et al., 2016 (54) & Yes & Croatia & 1330 & 16.6 & 0 & Student & $\mathrm{AD}$ & Other & .39 & .46 & .03 & - & - \\
\hline
\end{tabular}




\begin{tabular}{|c|c|c|c|c|c|c|c|c|c|c|c|c|c|}
\hline Rodriguez et al., 2015 (55) & Yes & USA & 252 & 23.1 & 40.5 & Student & $\mathrm{AD}$ & SOGS & .3 & .22 & .06 & $.28(.05)$ & $.24(.06)$ \\
\hline Russell et al., 2019 (56) & Yes & Australia & 1147 & 41.2 & 33.5 & Com & GOES & PGSI & .51 & .16 & .03 & $.26(.03)$ & $.05(.04)$ \\
\hline Schellenberg et al., 2016 (7) & Yes & Canada & 939 & 51.9 & 62 & Com & GMQ-F & PGSI & .45 & .40 & .03 & $.08(.03)$ & $.18(.03)$ \\
\hline Smith et al., 2012 (57) & Yes & USA & 194 & 39.5 & 2.6 & Com & GMQ-F & Other & .24 & .29 & .07 & - & - \\
\hline Sundqvist et al., 2016 (58) & Yes & Sweden & 257 & 49 & 30 & Com & Other & Other & .26 & - & .06 & $.13(.05)$ & - \\
\hline Tabri et al., 2015 (59) & Yes & USA & 196 & 37.9 & 48.5 & Com & GMQ-F & PGSI & .29 & - & .07 & $.11(.07)$ & - \\
\hline Tabri et al., 2017 (60) & Yes & USA & 220 & 36 & 46 & Com & GMQ-F & PGSI & .33 & - & .07 & $.17(.06)$ & - \\
\hline Tabri et al., 2019 (61) & No & Canada & 86 & 55.1 & 54.5 & Gamb & GMQ-F & PGSI & .56 & - & .11 & $.07(.09)$ & - \\
\hline Tabri et al., 2020 (62) & Yes & Canada & 5666 & 47.6 & 51.6 & Com & GMQ-F & PGSI & .27 & - & .01 & $.07(.01)$ & - \\
\hline
\end{tabular}




\begin{tabular}{|c|c|c|c|c|c|c|c|c|c|c|c|c|c|}
\hline Tao et al., 2011 (63) & Yes & China & 791 & 38.7 & 42.2 & Com & Other & Other & .42 & - & .04 & - & - \\
\hline Wohl, n.d. (64) & No & Canada & 405 & 58.7 & 56.9 & Gamb & GMQ-F & PGSI & .42 & - & .05 & $.29(.05)$ & - \\
\hline Wu \& Tang, 2011 (65) & Yes & China & 932 & 20.6 & 50.4 & Student & Other & SOGS & .29 & - & .03 & - & - \\
\hline Wu et al., 2012 (66) & Yes & China & 694 & 36.3 & 42.7 & Com & Other & Other & .58 & - & .04 & $.41(.04)$ & - \\
\hline \multicolumn{14}{|c|}{$\begin{array}{l}\text { Note. } \text { PUB = Publication Status; AD = Author-developed; GD = Gambling Disorder; GF = Gambling Frequency; Com = Community } \text { Clin = } \\
\text { Clinical; Indig = Indigenous; WO = Women; Gambesta = Gambling Establishment; PGSI = Problem Gambling Severity Index; GOES = Gambling } \\
\text { Outcomes Expectancies Scale; GMQ-F = Gambling Motives Questionnaire }- \text { Financial; SOGS = South Oaks Gambling Scale. }\end{array}$} \\
\hline
\end{tabular}


Financial motives and disordered gambling

Table 2. Results of moderator meta-regression analyses.

\begin{tabular}{|c|c|c|}
\hline & Disordered gambling severity & $\begin{array}{l}\text { Gambling } \\
\text { Frequency }\end{array}$ \\
\hline Moderator variable & $B(S E)$ & $B(S E)$ \\
\hline Mean age of the sample & $-.003(.002)$ & $-.01(.01)$ \\
\hline Gender (\% female) & $.0003(001)$ & $.001(.001)$ \\
\hline Publication status & $-.06(.08)$ & - \\
\hline \multicolumn{3}{|l|}{ Gambling motives measure } \\
\hline GMQ-F vs. author-developed & $.03(.08)$ & $-.30(.13) *$ \\
\hline GMQ-F vs. GOES & $.18(.09)$ & $-.14(.12)$ \\
\hline GMQ-F vs. Other & $.06(.08)$ & $-.19(.12)$ \\
\hline \multicolumn{3}{|l|}{ Geographical region } \\
\hline North America vs. Australasia & $-.15(.08)$ & $-.03(.10)$ \\
\hline North America vs. Europe & $-.01(.07)$ & $-.07(.10)$ \\
\hline North America vs. Asia & $.04(.10)$ & - \\
\hline North America vs. Argentina & $.02(.15)$ & - \\
\hline $\begin{array}{l}\text { Note. GMQ-F = Gambling Motives Q } \\
\text { Expectancies Scale. } * p<.05 .\end{array}$ & estionnaire - Financial; GOES & mbling Out \\
\hline
\end{tabular}


Figure 1. PRISMA Chart

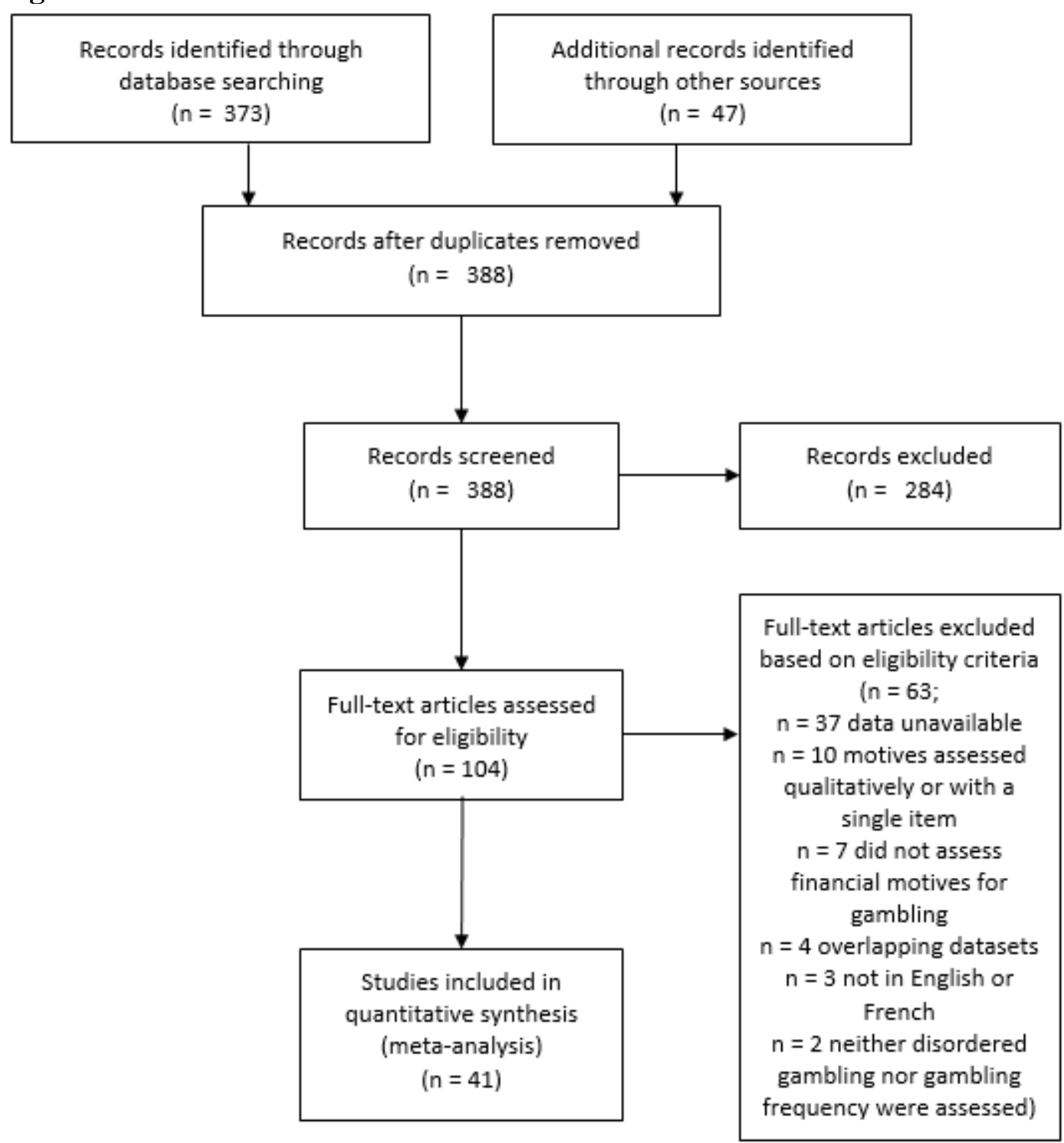


Figure 2. Forest plot of Fisher $Z_{r}$ effect sizes indexing the zero-order association between financial motivation for gambling and disordered gambling severity.

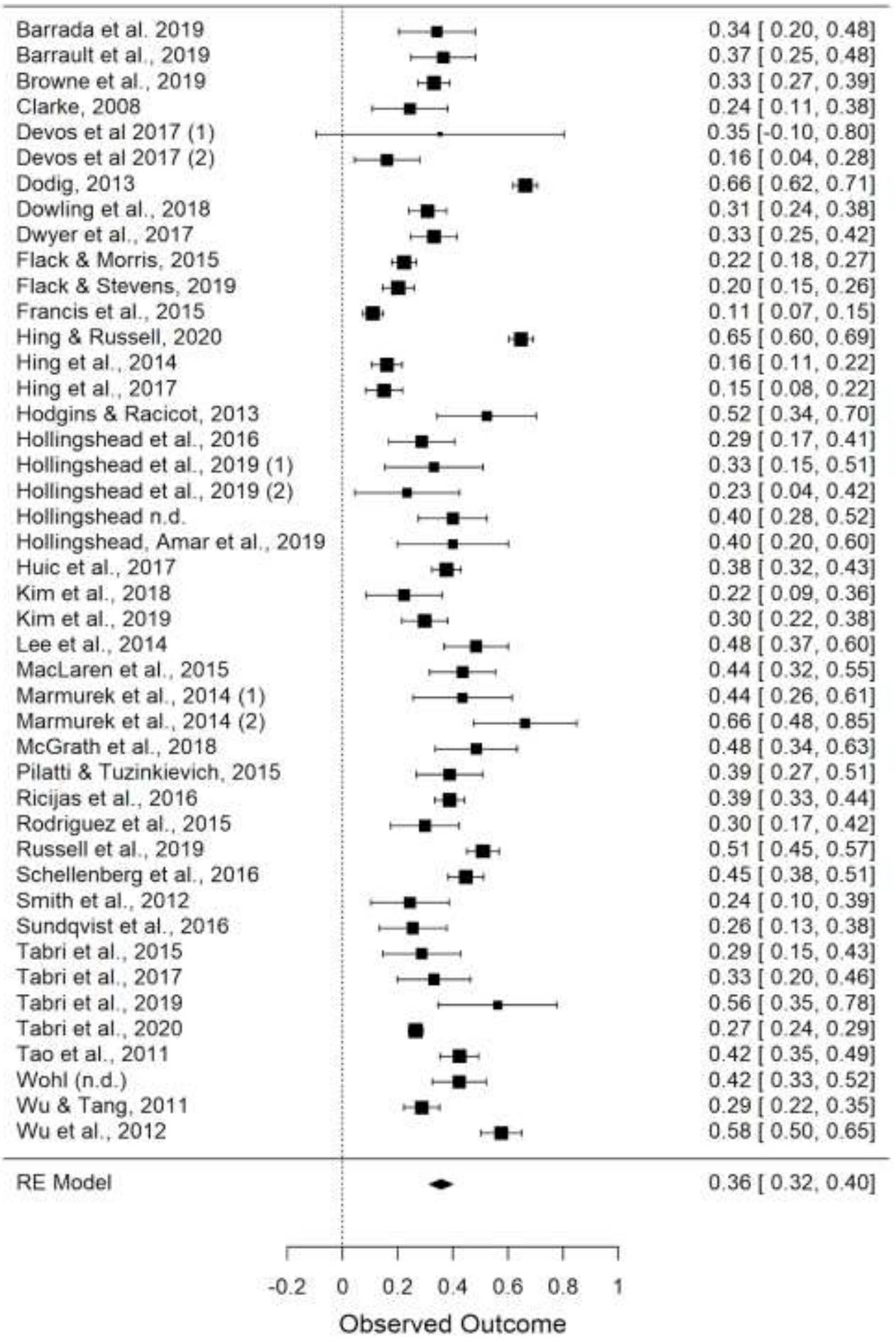


Figure 3. Forest plot of the standardized regression coefficients indexing the unique association between financial motivation for gambling and disordered gambling severity controlling for social, coping, and enhancement gambling motives.

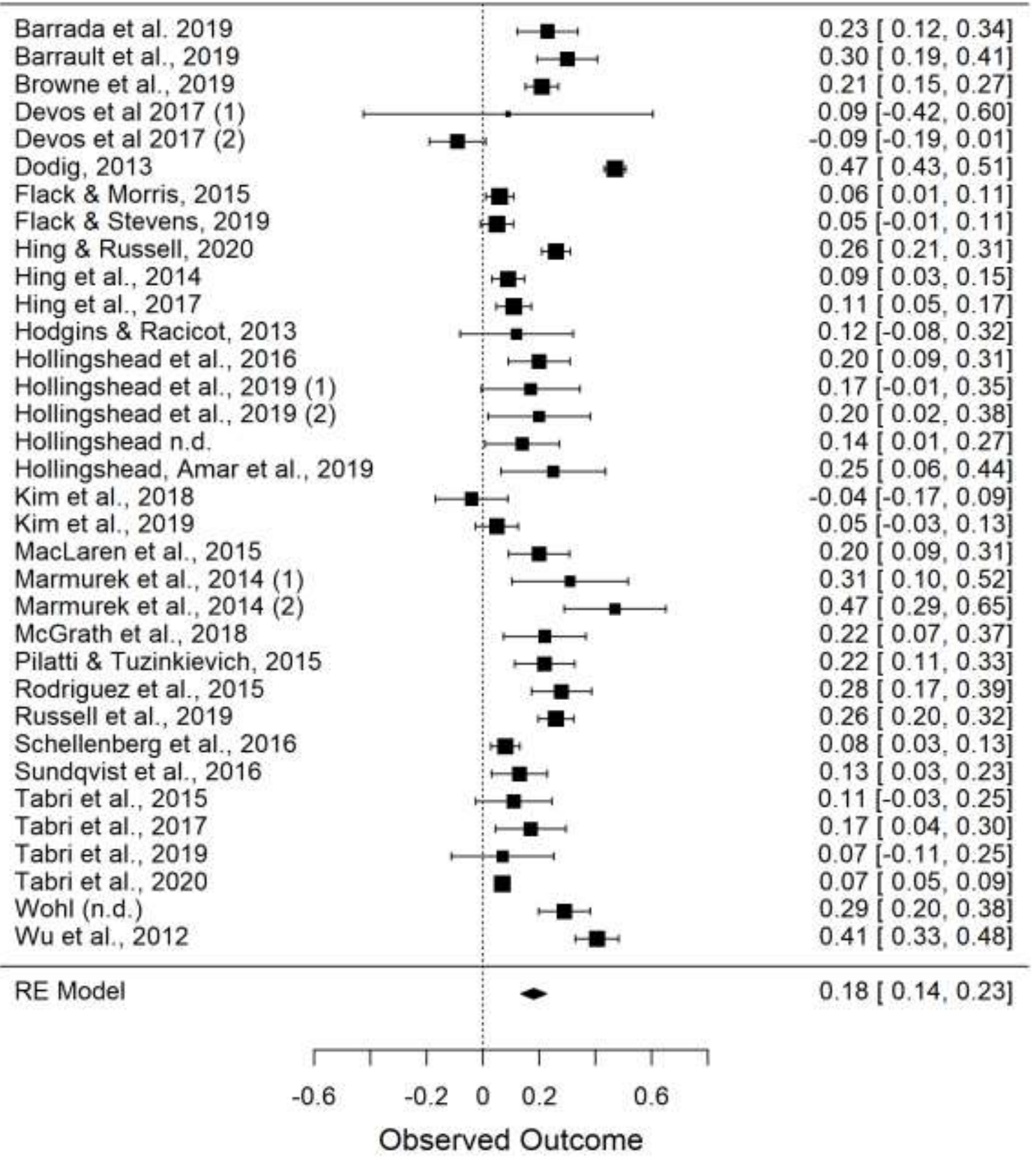


Figure 4. Forest plot of Fisher $Z_{r}$ effect sizes indexing the zero-order association between financial motivation for gambling and gambling frequency.

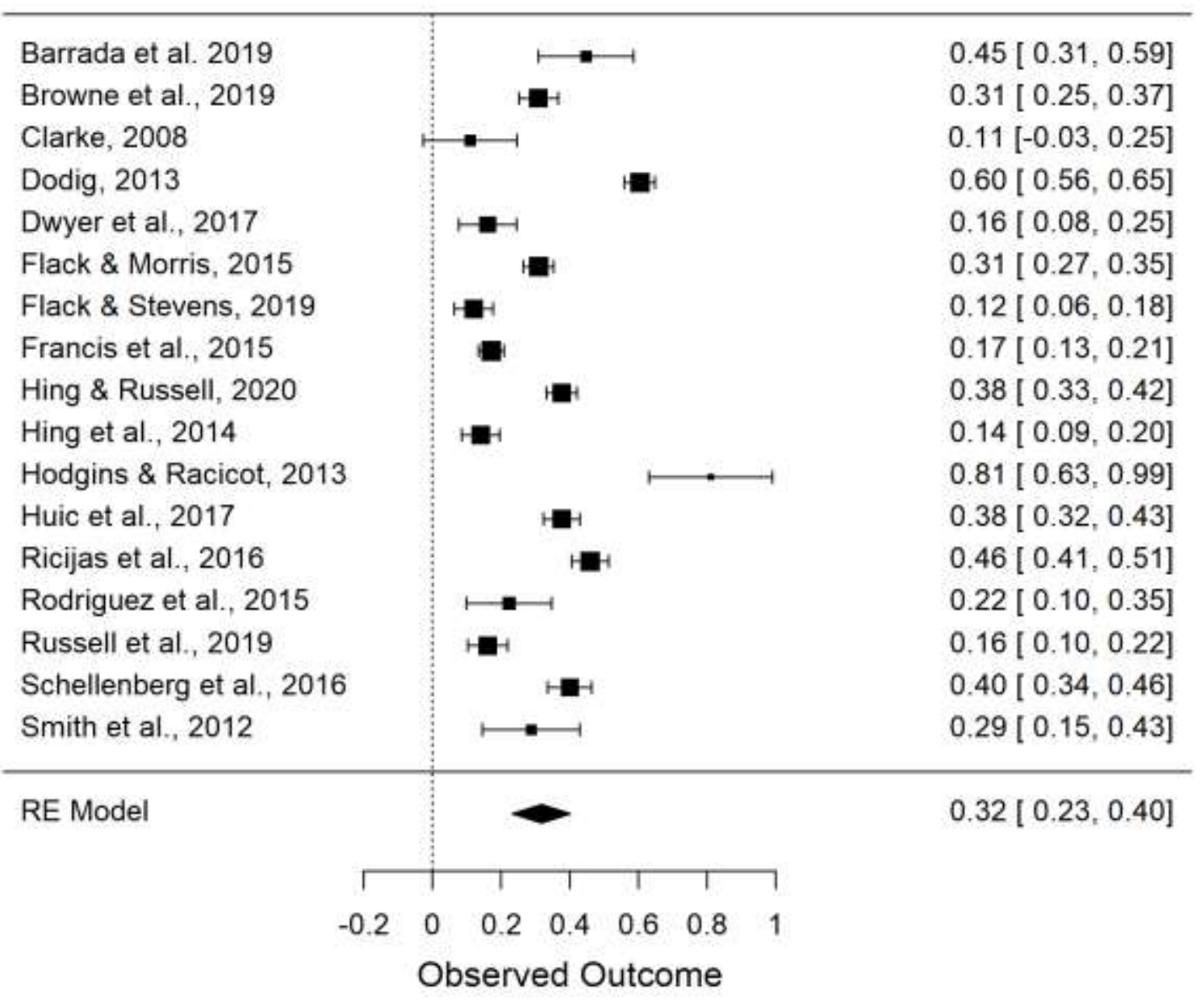


Figure 5. Forest plot of the standardized regression coefficients indexing the unique association between financial motivation for gambling and gambling frequency controlling for social, coping, and enhancement gambling motives.

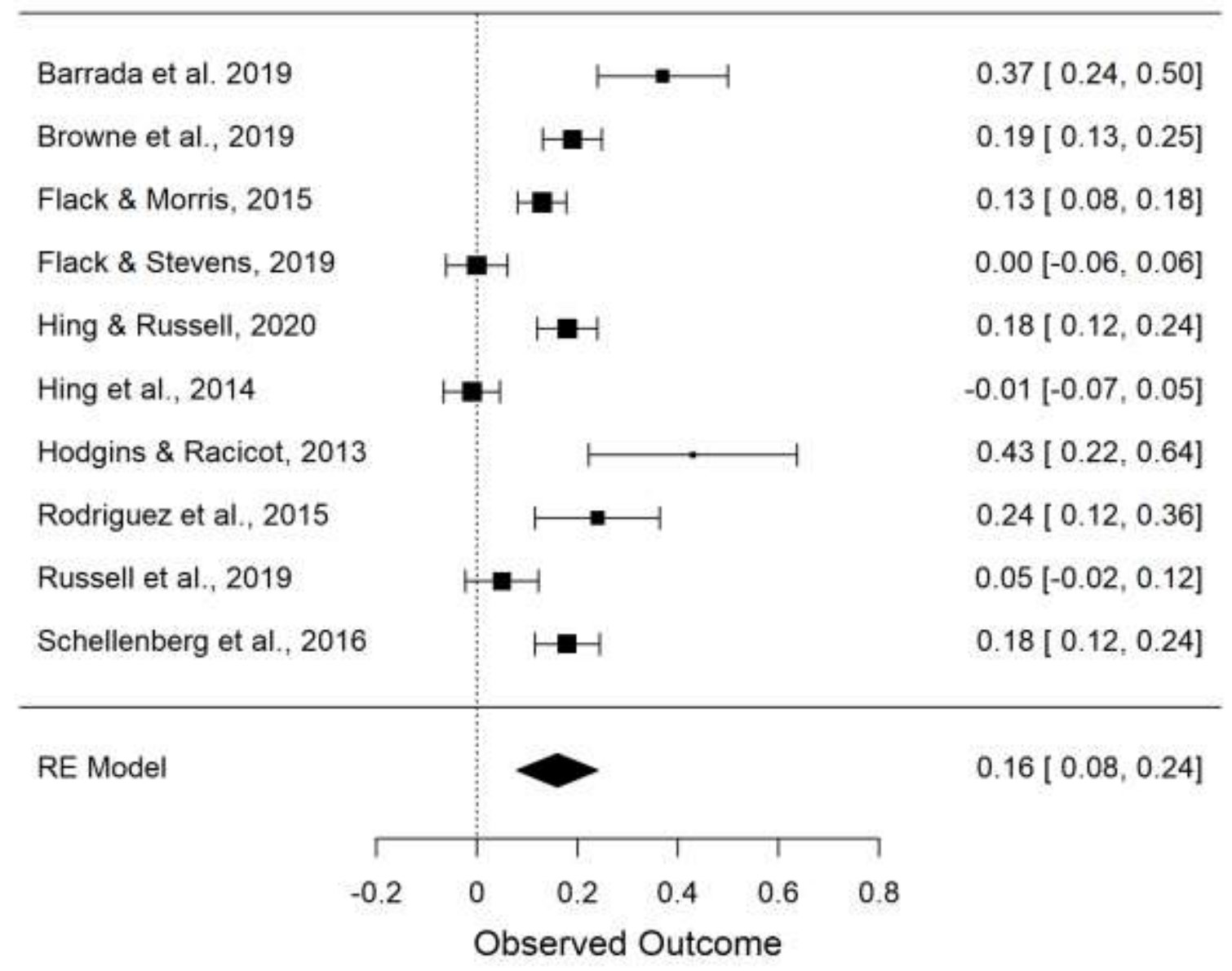

